\title{
The inhibitory effect of secretin on broth-stimulated gastric secretion in human subjects ${ }^{1}$
}

\author{
MARIO KAMIONKOWSKI, SEYMOUR GROSSMAN², AND BERTRAM FLESHLER \\ From the Western Reserve University School of Medicine at Cleveland \\ Metropolitan General Hospital, Cleveland, Ohio, U.S.A.
}

\begin{abstract}
EDITORIAL SYNOPSIS The effect of intravenous secretin on broth-stimulated gastric secretion was studied in 10 adult subjects. Secretin significantly inhibited gastric acid concentration and output for at least 30 minutes following administration. These results were not due to neutralization by reflux of pancreatic juice since the volume of gastric aspirate and the combined acid concentration were less with secretin than during the control study. No difference was observed between the degree of inhibition of gastric secretion of two different preparations of secretin. These findings in humans are similar to those reported in dogs and indicate that secretin may have a physiological role in inhibiting gastric secretion.
\end{abstract}

Gastric secretion of acid is inhibited when various substances come into contact with the duodenal mucosa (Thompson and Peskin, 1961). One of the substances which initiates this effect is hydrochloric acid. The mechanism whereby hydrochloric acid inhibits gastric acid production is disputed, some experiments suggesting that an intrinsic nervous pathway is involved (Code and Watkinson, 1955; Sircus, 1958) while others have indicated that a humoral factor may be released (Gregory, 1956). The inhibitory effect of hydrochloric acid does not occur until the $p \mathrm{H}$ in the duodenal lumen falls to or below $2 \cdot 5$. Lowering the duodenal $p \mathrm{H}$ to this level is also a potent stimulus to the release of secretin. Although the action of secretin on pancreatic secretion is well established, its possible role as a gastric acid inhibitor was first clearly suggested by Greenlee, Longhi, Guerrero, Nelsen, El-Bedri, and Dragstedt (1957) who demonstrated inhibition of food-stimulated gastric secretion in dogs with Heidenhain pouches given secretin intravenously. This work was confirmed recently in dogs (Jordan and Peterson, 1962; Kennedy and Hallenbeck, 1963). The present study was undertaken to assess the effect of secretin on the gastric phase of acid secretion in man.

'Supported in part by grant no. 319 from the Nutrition Foundation, Inc.

'Present address: 2 Van Wert Avenue, White Plains, New York, U.S.A.

\section{MATERIALS AND METHODS}

Adult patients on the general medical wards were utilized for the study. The subjects were free of known gastrointestinal disease except for subject L.S. who had a healed benign antral ulcer. Following a 12-hour period of fasting, each subject was intubated with a gastroduodenal double-lumen tube. The tube was positioned under fluoroscopic control so that gastric and duodenal contents could be aspirated separately. Suction was carried out with two aspiration pumps and the apparatus constantly monitored to insure patency of the system.

At the beginning of the study an intravenous infusion of $5 \%$ dextrose in water was started and continued throughout at a rate of $1 \mathrm{ml}$. per minute. Fasting gastric contents were collected for three 10-minute collection periods, then $80 \mathrm{ml}$. of an $0.8 \%$ solution of nutrient broth $^{3}$ was instilled into the stomach through the gastric tube. The gastroduodenal tube was then clamped for 10 minutes. Either secretin $(0.5$ units per kilogram of body weight) or saline was administered intravenously at the same time broth was instilled into the stomach. Three subsequent doses of secretin ( 0.5 units per kilogram of body weight) or saline were administered at 15-minute intervals. Following the 10-minute period during which no aspiration was carried out, gastric and duodenal contents were aspirated for five minutes and discarded. The total contents were then collected for six consecutive 10-minute periods. Duodenal fluid was discarded and the gastric aspirates analysed. Aspiration thus was carried

${ }^{3}$ Eight grams of dehydrated nutrient broth (Difco Laboratories) dissolved in 1 litre of distilled water and autoclaved for 15 minutes at $15 \mathrm{lb}$. pressure $\left(121^{\circ} \mathrm{C}\right.$.). 
out for 30 minutes following the last intravenous injection. Immediately following the six 10-minute collection periods, a protocol similar to the one outlined above was repeated beginning with instillation of the broth. In those subjects who received secretin initially, saline was given during the second part of the study; in the others, the order was reversed. Five were given saline first, the other five received secretin initially. The order in which secretin and saline were administered did not influence the results. The first eight subjects received the Lilly Company secretin $^{4}$, the other two received secretin prepared by Vitrum ${ }^{5}$.

The volume of each 10-minute collection of gastric juice was determined and the $p \mathrm{H}$ measured using a Radiometer $p \mathrm{H}$ meter, model $22^{6}$. The $p \mathrm{H}$ units were converted to $\left(\mathrm{H}^{+}\right)$in $\mathrm{mEq} . / 1$. Each sample was titrated with $0 \cdot 1 \mathrm{~N} \mathrm{NaOH}$ to $p \mathrm{H} 4$ for 'free acid' concentration and to $p \mathrm{H} 8$ for total acid concentration. Combined acid concentration was figured as the difference between the total and free acid concentrations. Free and total acid outputs were calculated by multiplying concentration by volume. Analysis of the data was carried out by estimation of the standard error of the mean, Student's $t$ value (Snedecor, 1962).

\section{RESULTS}

Figure 1 shows the results of a typical experiment and illustrates the protocol used. Following 30 minutes of basal collection, broth was instilled into the stomach and secretin administered intravenously at the times indicated. In the second part of the study, broth was again instilled into the stomach and saline given intravenously instead of secretin. In this study secretin inhibited the gastric secretory response to broth by reducing both the volume of gastric juice and concentration of acid.

Table I compares the free hydrochloric acid concentration of the fasting gastric contents with the free hydrochloric acid concentration of the gastric contents obtained during the 60 minutes following evacuation of broth. When saline was administered gastric acid concentration following broth was significantly greater than basal values $(\mathrm{P}<0.01)$. Thus broth given under these conditions appeared to stimulate gastric acid secretion effectively. During administration of secretin, however, there was no real increase over basal values when broth was instilled $(P>0 \cdot 1)$.

The results of administration of secretin and saline on broth-stimulated gastric secretion are shown in Table Il. Free hydrochloric acid concentration was less in all subjects following secretin than with administration of saline $(\mathrm{P}<0.01)$. The hydrogen ion concentration, calculated from the $p \mathrm{H}$ values,

${ }^{4}$ Generously supplied by Eli Lilly and Company.

${ }^{3}$ Vitrum, Stockholm, Sweden.

${ }^{\theta}$ Radiometer, Copenhagen, Denmark.

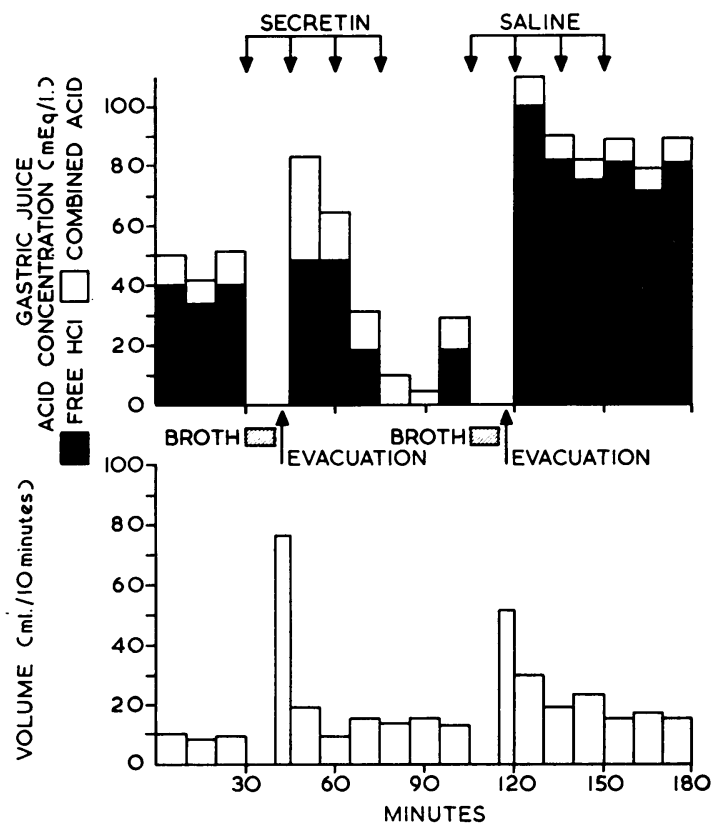

FIG. 1. Effect of intravenous secretin contrasted with effect of saline injection on broth-stimulated gastric secretion (subject H.N.). Thirty minutes of basal collection preceded the first instillation of broth.

\section{TABLE I}

FREE HCL CONCENTRATION (MEq./1.) OF BROTH-STIMULATED GASTRIC SECRETION DURING SALINE AND SECRETIN ADMINISTRATION COMPARED WITH CONCENTRATION DURING BASAL PERIOD

\begin{tabular}{|c|c|c|c|}
\hline Subject & Basal & Saline & Secretin \\
\hline M.K. & $1 \cdot 0$ & $48 \cdot 3$ & 30.8 \\
\hline L.S. & $8 \cdot 5$ & $34 \cdot 3$ & 10.5 \\
\hline I.J. & 0 & $4 \cdot 3$ & 0 \\
\hline H.N. & 37.0 & $81 \cdot 6$ & $22 \cdot 0$ \\
\hline G.J. & $7 \cdot 5$ & $49 \cdot 3$ & 10.5 \\
\hline E.T. & 0 & $26 \cdot 3$ & $19 \cdot 6$ \\
\hline M.B. & 0 & $20 \cdot 3$ & $5 \cdot 0$ \\
\hline C.L. & 16.6 & 17.8 & $1 \cdot 3$ \\
\hline H.O. & $24 \cdot 1$ & 51.8 & 26.9 \\
\hline J.W. & 0 & $24 \cdot 0$ & 0 \\
\hline Mean & $9 \cdot 5$ & $35 \cdot 8$ & $12 \cdot 6$ \\
\hline$P$ value & \multicolumn{2}{|c|}{$\begin{array}{c}\text { Basal vs. saline } \\
<0.01\end{array}$} & $\begin{array}{c}\text { Basal vs. secretin } \\
>0 \cdot 1\end{array}$ \\
\hline
\end{tabular}

similarly was less $(\mathbf{P}<\mathbf{0} \cdot \mathbf{0 1})$ when secretin was compared with saline. The total concentration and also the free and total output of acid were decreased during administration of secretin. Less gastric juice was recovered during the 60 minutes following broth evacuation with secretin administration than with saline in eight of the 10 subjects. This difference was not statistically significant $(P>0 \cdot 1)$. The concentration of combined acid following broth evacuation was less following secretin administration than with 
TABLE II

EFFECT OF INTRAVENOUS SALINE AND SECRETIN ON GASTRIC ACID CONCENTRATION AND OUTPUT FOR THE 60 MINUTES FOLLOWING STIMULATION OF GASTRIC SECRETION BY BROTH

\begin{tabular}{|c|c|c|c|c|c|c|c|c|c|c|}
\hline \multirow[t]{2}{*}{ Subject } & \multicolumn{2}{|c|}{$\begin{array}{l}\text { Free } \mathrm{HCl} \text { Con- } \\
\text { centration }(m E q . / 1 .)\end{array}$} & \multicolumn{2}{|c|}{$\begin{array}{l}\text { Total Acid Con- } \\
\text { centration }(m E q . / 1 .)\end{array}$} & \multicolumn{2}{|c|}{$\begin{array}{l}\text { Volume }(\mathrm{ml} .160 \\
\text { minutes) }\end{array}$} & \multicolumn{2}{|c|}{$\begin{array}{l}\text { Total Free } \mathrm{HCl} \\
\text { Output }(\mathrm{mEq} .)\end{array}$} & \multicolumn{2}{|c|}{$\begin{array}{l}\text { Total Acid Output } \\
\text { (mEq.) }\end{array}$} \\
\hline & Secretin & Saline & Secretin & Saline & Secretin & Saline & Secretin & Salıne & Secretin & Saline \\
\hline $\begin{array}{l}\text { M.K. } \\
\text { L.S. } \\
\text { I.J. } \\
\text { H.N. } \\
\text { G.J. } \\
\text { E.T. } \\
\text { M.B. } \\
\text { C.L. } \\
\text { H.O. } \\
\text { J.W. }\end{array}$ & $\begin{array}{c}30 \cdot 8 \\
10 \cdot 5 \\
0 \\
22 \cdot 0 \\
10 \cdot 5 \\
19 \cdot 6 \\
5 \cdot 0 \\
1 \cdot 3 \\
26 \cdot 9 \\
0\end{array}$ & $\begin{array}{r}48 \cdot 3 \\
34 \cdot 3 \\
4 \cdot 3 \\
81 \cdot 6 \\
49 \cdot 3 \\
26 \cdot 3 \\
20 \cdot 3 \\
17 \cdot 8 \\
51 \cdot 8 \\
24 \cdot 0\end{array}$ & $\begin{array}{r}52 \cdot 0 \\
22 \cdot 5 \\
5 \cdot 0 \\
26 \cdot 8 \\
23 \cdot 1 \\
37 \cdot 5 \\
9 \cdot 1 \\
6 \cdot 7 \\
30 \cdot 9 \\
3 \cdot 9\end{array}$ & $\begin{array}{l}80 \cdot 3 \\
44 \cdot 6 \\
14 \cdot 6 \\
89 \cdot 6 \\
63 \cdot 8 \\
43 \cdot 0 \\
26 \cdot 2 \\
27 \cdot 9 \\
50 \cdot 2 \\
29 \cdot 0\end{array}$ & $\begin{array}{r}53.0 \\
129.0 \\
107.0 \\
87.0 \\
70.0 \\
89.0 \\
26.0 \\
46.0 \\
62.5 \\
19.0\end{array}$ & $\begin{array}{r}69 \cdot 0 \\
136 \cdot 0 \\
52 \cdot 0 \\
119 \cdot 0 \\
101 \cdot 0 \\
104 \cdot 0 \\
237 \cdot 0 \\
24 \cdot 0 \\
69 \cdot 0 \\
73 \cdot 5\end{array}$ & $\begin{array}{l}1.73 \\
1.20 \\
0 \\
1.86 \\
0.61 \\
1.98 \\
0.75 \\
0.08 \\
0.27 \\
0\end{array}$ & $\begin{array}{l}2.67 \\
4.41 \\
0.38 \\
9.94 \\
5.08 \\
1.91 \\
4 \cdot 18 \\
0.49 \\
0.60 \\
0.40\end{array}$ & $\begin{array}{l}3.34 \\
2.71 \\
0.03 \\
3 \cdot 16 \\
1.41 \\
3.95 \\
0.85 \\
0.27 \\
2.27 \\
0.09\end{array}$ & $\begin{array}{r}5 \cdot 33 \\
5 \cdot 85 \\
0 \cdot 96 \\
10 \cdot 86 \\
6 \cdot 45 \\
4 \cdot 55 \\
8 \cdot 30 \\
0 \cdot 60 \\
4 \cdot 19 \\
3 \cdot 00\end{array}$ \\
\hline $\begin{array}{l}\text { Mean } \\
\text { P value }\end{array}$ & $12 \cdot 6$ & $\begin{array}{l}35 \cdot 8 \\
01\end{array}$ & $21 \cdot 7$ & $\begin{array}{l}46.9 \\
01\end{array}$ & $68 \cdot 8>$ & $\begin{array}{l}98 \cdot 4 \\
\cdot 1\end{array}$ & $0 \cdot 84$ & $\begin{array}{l}2.99 \\
.05\end{array}$ & 1.80 & $01^{5 \cdot 00}$ \\
\hline
\end{tabular}

saline administration, but the difference was not significant $(\mathrm{P}>\mathbf{0} \cdot \mathbf{1})$.

Table III compares the average free hydrochloric acid concentration during saline and secretin administration for the six separate 10-minute collection periods. Free hydrochloric acid concentration was significantly lower after secretin than after saline in each time period.

\section{TABLE III}

EFFECT OF INTRAVENOUS SECRETIN AND SALINE ON FREE HCL CONCENTRATION (mEq./1.) FOR EACH 10-MINUTE COLLECTION PERIOD AFTER STIMULATION OF GASTRIC SECRETION BY BROTH

\begin{tabular}{llllllc} 
& \multicolumn{1}{l}{ Period } & & & \\
\cline { 2 - 7 } & 1 & 2 & 3 & 4 & 5 & 6 \\
\hline Saline & 33.0 & 51.8 & 38.2 & 32.9 & 23.4 & 30.4 \\
Secretin & 13.2 & 23.5 & 15.9 & 11.6 & 4.2 & 4.7 \\
P value & $<0.05$ & $<0.01$ & $<0.05$ & $<0.05$ & $<0.05$ & $<0.01$
\end{tabular}

\section{DISCUSSION}

In these studies in man the intravenous administration of secretin produced a significant inhibition of broth-stimulated gastric secretion. The results are consistent with those reported in animals (Greenlee et al., 1957; Jordan and Peterson, 1962; Kennedy and Hallenbeck, 1963) and confirm the action of secretin on gastric secretion. The inhibition of brothstimulated secretion appears to be specific since secretin failed to inhibit ethanol, histamine, or insulin-stimulated secretion in animals (Thomford, Kennedy, and Hallenbeck, 1963; Greenlee et al., 1957).

Secretin produces a copious outflow of alkaline pancreatic juice. Neutralization of gastric acid by reflux could explain the results obtained. In an effort to decrease the amount of pancreatic secretion available for reflux and neutralization duodenal juice was aspirated separately. Furthermore, if neutralization by reflux of alkaline juice were responsible for the decreased acidity, the volume of gastric aspirate should have been greater. Instead, the volume was less in eight of the 10 subjects. Combined acid, which has been used as a measure of reflux (Rovelstad, 1963), should have been significantly higher if reflux and neutralization were important factors. The values for combined acid when secretin was given were lower, although not significantly so, than those during administration of saline. A similar inhibitory effect on gastric secretion was demonstrated in pancreatectomized dogs (Kennedy and Hallenbeck, 1963), an experimental preparation which eliminates pancreatic juice as a contributory factor. These findings indicate that the secretin effect is a direct one, rather than one operating through reflux.

The inhibitory effect of secretin has been demonstrated with preparations whose purity differs widely (Jordan and Peterson, 1962; Kennedy and Hallenbeck, 1963). Both in experiments in dogs and in these studies in humans, inhibition occurred with different preparations, suggesting that inhibition is due to secretin itself rather than to any contaminant. The exact amount required to produce inhibition and the relationship between the amount administered and the quantity of secretin released under normal circumstances are not known. The inhibitory effect was observed for at least 30 minutes following the last dose.

The physiological importance of the secretin effect is yet to be determined. Whether abnormalities of secretin inhibition play a role in human disease is unknown. The observations both in dogs and in humans are consistent with the hypothesis that acid introduced into the duodenum inhibits gastric secretion through a humoral mechanism, i.e., the release of endogenous secretin. 


\section{REFERENCES}

Code, C. F., and Watkinson, G. (1955). Importance of vagal innervation in the regulatory effect of acid in the duodenum on gastric secretion of acid. J. Physiol. (Lond.), 130, 233-252.

Greenlee, H. B., Longhi, E. H., Guerrero, J. D., Nelsen, T. S., El-Bedri, A. L., and Dragstedt, L. R. (1957). Inhibitory effect of pancreatic secretion on gastric secretion. Amer. J. Physiol., 190, 396-402.

Gregory, R. A. (1956). Motor and secretory inhibition of duodenal origin in transplanted gastric pouches. J. Physiol. (Lond.), 132, 67P-68P.

Jordan, P. H. Jr., and Peterson, N. D. (1962). Effects of secretin upon gastric secretion. Ann. Surg., 156, 914-923.
Kennedy, J. A., and Hallenbeck, G. A. (1963). The pancreas and gastric secretion: failure of pancreatectomy to prevent inhibition of gastric secretion by secretin. Gut, 4, 58-60.

Rovelstad, R. A. (1963). Gastric analysis. Gastroenterology, 45, 90-107.

Sircus, W. (1958). Studies on the mechanisms in the duodenum inhibiting gastric secretion. Quart. J. exp. Physiol., 43, 114-133.

Snedecor, G. W. (1962). Statistical Methods. Ames, Iowa State University Press.

Thomford, N. R., Kennedy, J. A., and Hallenbeck, G. A. (1963). Failure of secretin or duodenal acidification to inhibit ethanolinduced $\mathrm{HCl}$ secretion by Heidenhain pouches. Proc. Soc. exp. Biol. (N.Y.), 112, 1000-1002.

Thompson, J. C., and Peskin, G. W. (1961). The intestinal phase of gastric secretion. Amer. J. med. Sci., 241, 253-262. 